\title{
A Study on Steel-Concrete-Steel Wall to Resist Perforation from Rigid Projectile Impact
}

\author{
Pengfei Han $\mathbb{D}^{1,2}{ }^{1,2}$ Jingbo Liu, ${ }^{1}$ Bigang Fei, ${ }^{2}$ and Fei Wang ${ }^{1}$ \\ ${ }^{1}$ Key Laboratory of Civil Engineering Safety and Durability of China Education Ministry, Department of Civil Engineering, \\ Tsinghua University, Beijing 100084, China \\ ${ }^{2}$ State Quality (Beijing) Construction Engineering Testing \& Appraisal Center, Beijing 100081, China
}

Correspondence should be addressed to Pengfei Han; feixuehan2003@sina.com

Received 11 March 2021; Revised 9 July 2021; Accepted 28 July 2021; Published 6 September 2021

Academic Editor: Hongyuan Zhou

Copyright ( $\odot 2021$ Pengfei Han et al. This is an open access article distributed under the Creative Commons Attribution License, which permits unrestricted use, distribution, and reproduction in any medium, provided the original work is properly cited.

\begin{abstract}
A calculation method of SCS wall which is used in the third generation of nuclear power plants to resist perforation from rigid projectile based on energy method is proposed in this paper. The energy is divided into four parts including the energy dissipated by front steel plate, concrete, back steel plate, and tie bars. The method accounts for the perforation of the concrete and steel plates separately and accounts for the interaction between them, and a practical antiperforation calculation formula of SCS wall with tie bars is given. The most formular results are close to the test results and the FEM results with a deviation less than $10 \%$, which shows that the calculation formula given in this paper is reasonable and credible to effectively evaluate the perforation failure of the SCS wall and carry out a relevant design. The energy dissipated by the steel plate is much larger than that of the tie bars through a comparative analysis of dissipated energy. The effects of various factors on perforation velocity are analyzed according to finite element calculation results, which can be roughly divided into three categories: the influence of the thickness of steel plate and distance of tie bar is the largest effect, followed by that of yield strength of steel plate, yield strength of tie bar and diameter of tie bar, and that of compressive strength of concrete is the smallest effect.
\end{abstract}

\section{Introduction}

Steel-concrete-steel (SCS) sandwich wall is constructed with steel surface plates that act as concrete reinforcement. The tie bars and shear studs are welded to the steel faceplates to develop the composite behaviour of the steel faceplates and concrete. The SCS walls are used in the shield building of the third generation of nuclear power plants to keep the internal steel containment and reactor cooling system from damage by external events. It is important, therefore, that researchers need to study local damage caused by aircraft engine or missile impact, for example, perforation analysis is one of the important research contents. And engineers need an accurate and convenient calculation method to design SCS walls for resisting aircraft engine or missile impact.

Due to the demands of military and nuclear industries, reinforced concrete (RC) targets against perforation of missile have been widely studied with valuable test data and relevant empirical formulas by researchers, such as Petry formula, ACE formula, CEA-EDF formula, UKAEA formula, NDRC formula, and Kar formula. Kennedy [1] made a detailed review of empirical formulas of thick concrete targets against perforation of missile impact, which basically covered test data of European and American countries before the 1970s of the last century. Bangash [2] summarized empirical formulas of RC perforation in different periods, Ranjan et al. [3], Williams [4], and Wen [5] compared results of different empirical formulas for RC perforation with numerical analyses and test data, and Li et al. [6] discussed empirical formulas for RC perforation recently published in detail. These empirical formulas provide a direct and convenient suggestion for the perforation prevention design of RC structures, but the empirical formulas also have their own limitations, which cannot make perforation prediction results to be in good agreement with the test data under all conditions. 
Song et al. [7] and Feng et al. [8] established a design and calculation method of antiperforation of RC containment and performed parameter analyses, which considered the effects of various reinforcing bars. Based on the cavity expansion theory, Li et al. $[9,10]$ and Chen et al. [11] gave the formulas for calculating the minimum concrete thickness and energy of a rigid projectile perforating a plain concrete wall. The calculated results of the formulas are in good agreement with the experimental results, and a perforation calculation method of RC wall against rigid projectile was given.

SCS wall is a new type of structure compared with RC wall, and the research and calculation method of perforation of SCS wall is not widely available. Grisaro and Dancygier [12] gave an antiperforation formula for calculating the minimum thickness of RC wall with a rear steel plate, which was obtained by combining the existing formulas for calculating the perforations of RC and steel plate against rigid projectile, respectively, and the result from the given formula was in good agreement with the experimental data. Siddiqui et al. [13] conducted a series of perforation tests of RC shielded steel plates against rigid projectiles; in such structures, the RC plate and steel plate were separated and RC plate surrounded the inner steel plate. The damage characteristics of the inner steel plate against the impact of ogive and biconical shaped projectiles were studied. Finally, quantitatively evaluate how safe the steel plate is under the impact of these projectiles by using the available perforation formulas of the RC plate and steel plate. Bruhl et al. [14] presented a calculation method for the perforation design of SCS wall subjected to rigid projectile impact without considering the effect of tie bars and the front steel plate.

A calculation method of SCS wall to resist perforation from rigid projectile based on energy method is proposed in this paper, which accounts for the perforation of the concrete and steel plates separately and accounts for the interaction between them, and a practical antiperforation calculation formula of SCS wall with tie bars is given. The rationality and feasibility of the given calculation formula are verified by comparing its calculation results with existing test data and finite element analysis results, and the effect of various factors on perforation velocity is analyzed by the finite element method (FEM).

\section{Establishment of Calculation Method of SCS Wall to Resist Perforation}

This calculation method is based on the energy method. When a projectile normally impacts the SCS wall with tie bars under the condition that the translational constraint around the SCS wall is performed along the impact direction of the projectile, then the perforation energy dissipation can be divided into four parts: (I) energy dissipation of the front steel plate, (II) energy dissipation of the concrete (III) energy dissipation of the rear steel plate, and (IV) energy dissipation of the tie bars. The residual velocity is zero after perforation in case of the critical condition; then the following equation as is true according to the conservation of energy:

$$
E_{k}=W_{s 1}+W_{\text {con }}+W_{s 2}+W_{t}
$$

where $E_{k}$ is the initial kinetic energy of the projectile, $W_{s 1}$ is the energy dissipation of the front steel plate, $W_{\text {con }}$ is the energy dissipation of the concrete, $W_{s 2}$ is the energy dissipation of the rear steel plate, $W_{t}$ is the energy dissipation of the tie bars. The local failure mechanism associated with projectile impact on SCS wall is that (I) the projectile is assumed to penetrate the front steel plate and dislodge a steel disk, (II) the original projectile and the steel disk become a projectile impacting the concrete and dislodge a circular truncated cone of concrete with cracked tie bars, (III) the original projectile, the steel disc and the concrete plug with cracked tie bars impact the rear steel plate. As shown in Figure 1, $\theta$ is the angle between the generatrix of the circular truncated cone and the impact direction.

2.1. The Energy Dissipation of the Front Steel Plate. Chen et al. [15] used cavity expansion theory to propose a formula of perforation velocity of the rigid projectile impacting metal plate. The calculation results of this formula are in good agreement with the relevant experimental results. The formula for calculating the energy dissipated by the front steel plate is shown in equation (2), and the perforation velocity is shown in equation (3) by Chen et al. [15]:

$$
\begin{aligned}
W_{s 1} & =\frac{1}{2} M_{1} V_{b l s 1}^{2}, \\
V_{b l s 1} & =\sqrt{\frac{A N_{1} \sigma}{B N_{2} \rho_{s}}\left[\exp \left(\frac{\pi H_{s}}{2 d N}\right)-1\right]} \\
A & =\frac{1}{\sqrt{3}}\left(1+\left(\frac{E_{s}}{\sqrt{3} \sigma}\right)^{n} \int_{0}^{1-\left(\sqrt{3} \sigma / E_{s}\right)} \frac{(-\ln (x))^{n}}{1-x} \mathrm{~d} x\right), \\
N & =\frac{M_{1}}{\rho_{s} B N_{2} d^{3}},
\end{aligned}
$$

where $M_{1}$ is the mass of projectile, $d$ is the diameter of projectile, $V_{b l s 1}$ is the perforation velocity, $\sigma$ is the yield strength of steel plate, $\rho_{s}$ is the density of steel plate, $H_{s}$ is the depth of steel plate, $A$ and $B$ are the dimensionless material parameters of steel plate, $A$ is defined as equation (4) by Forrestal and Warren [16], $B$ is equal to $1.1, E_{s}$ is the elastic modulus of steel plate, $n$ is the strain hardening exponent, $N_{1}$ and $N_{2}$ are the geometric parameters of the projectile nose, and $N$ is the geometric parameter of projectile defined by equation (5).

2.2. The Energy Dissipation of the Concrete. Kar [17] proposed a formula as shown in equation (6) for calculating $\theta$ of the circular truncated cone when plain concrete against a projectile. In this paper, $\theta$ of the circular truncated cone in SCS wall is approximately calculated by this formula, where $H_{c}$ is the depth of concrete and $d$ is the diameter of projectile. The perforation velocity of the plain concrete is 


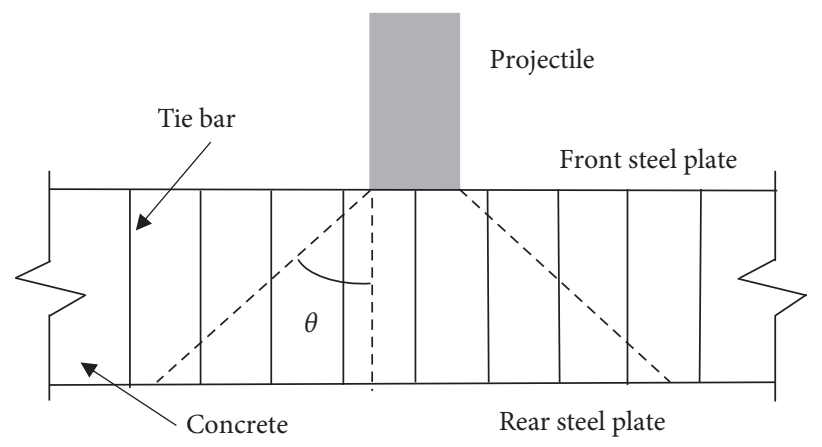

FIGURE 1: SCS wall with tie bars against projectile impact.

given by Li et al. [6] as shown in equation (7), where $V_{b l c}$ is the perforation velocity of the concrete; $f_{c}$ is the compressive strength of concrete; $k, S$, and $Y$ are the calculation parameters defined by equations (8) (10); and $h$ is the length of projectile nose. The formula for calculating the energy dissipated by the concrete is shown in equation (11):

$$
\begin{aligned}
\theta & = \begin{cases}\frac{45^{\circ}}{\left(H_{c} / d\right)^{1 / 3}}, & \left(\frac{H_{c}}{d}\right) \geq \frac{27}{64}, \\
60^{\circ}, & \left(\frac{H_{c}}{d}\right)<\frac{27}{64},\end{cases} \\
V_{b l c} & = \begin{cases}\sqrt{\frac{d^{3} f_{c} k \pi S}{3 M_{2}}}\left(\frac{Y-1}{2 S \tan \theta}\right), & Y \leq 1+\sqrt{3} S \tan \theta, \\
\sqrt{\frac{d^{3} f_{c} \pi S}{2 M_{2}}}\left(\frac{H_{c}}{d}-\frac{k}{2}-\frac{\sqrt{\sqrt{3} S \tan \theta+1}-1}{2 \tan \theta}\right)^{0.5}, & Y>1+\sqrt{3} S \tan \theta,\end{cases} \\
Y & =\frac{3 S^{2}}{16 k^{2}\left\{\sqrt{1+\frac{8 k}{\sqrt{3} S}\left(1+\frac{2 k}{\sqrt{3} S}+2\left(\frac{H_{c}}{d}\right) \tan \theta\right)}-1\right\}^{2}} \\
S & =72 f_{c}^{-0.5}, \\
k & =0.707+\frac{h}{d}, \\
W_{\text {con }} & =\frac{1}{2}\left(M_{1}+\rho_{s} \pi\left(\frac{d}{2}\right)^{2} H_{s}\right) V_{b l c}^{2} .
\end{aligned}
$$

2.3. The Energy Dissipation of the Rear Steel Plate. The formula for calculating the energy dissipated by the rear steel plate is shown in equation (12), the perforation velocity $V_{b l s 2}$ is shown in equation (13), and $N$ is defined by equation (14), where $\rho_{c}$ is the density of concrete: 


$$
\begin{aligned}
W_{s 2} & =\frac{1}{2}\left(M_{1}+\rho_{s} \pi\left(\frac{d}{2}\right)^{2} H_{s}+\frac{\pi}{3} \rho_{c} H_{c}\left(\left(\frac{d}{2}\right)^{2}+\frac{d}{2}\left(\frac{d}{2}+H_{c} \tan \theta\right)+\left(\frac{d}{2}+H_{c} \tan \theta\right)^{2}\right)\right) V_{b l s 2}{ }^{2}, \\
V_{b l s 2} & =\sqrt{\frac{A N_{1} \sigma}{B N_{2} \rho_{s}}\left[\exp \left(\frac{\pi H_{s}}{2 d N}\right)-1\right]}, \\
N & =\frac{M_{1}+\rho_{s} \pi(d / 2)^{2} H_{s}+\pi / 3 \rho_{c} H_{c}\left((d / 2)^{2}+(d / 2)\left((d / 2)+H_{c} \tan \theta\right)+\left((d / 2)+H_{c} \tan \theta\right)^{2}\right)}{\rho_{s} B N_{2} d^{3}}
\end{aligned}
$$

At this stage, the diameter of the formed projectile contact with the rear steel plate is taken as $d$ to account for the fact that a portion of the impacting concrete surface will crush and thus the entire diameter of the circular truncated cone plug does not impact the steel plate as a rigid projectile. Compared with the total mass of concrete plug, projectile, and disk of the front steel plate, the mass of tie bars cracked in the concrete plug is so small that they can be omitted.

2.4. The Energy Dissipation of the Tie Bars. The tie bars play a similar role as the stirrup in the RC wall for the circular truncated cone plug in the SCS wall. Under the impact load, the bond stress between tie bars and concrete is mainly concentrated in the crack edge area. Outside this area, the tie bars and concrete work together, and the strain of the tie bars in this part of the area is almost zero. The effective deformation length of the tie bar may be defined in equation (15), where $l_{e}$ is the effective deformation length of the tie bar, $\varepsilon_{s t}$ is the fracture strain of tie bar, $l_{a}$ is the transfer distance of bond stress, which can be defined in equation (16) from a Chinese code [18], where $\alpha$ and $\zeta$ are the conversion coefficients of anchorage length, $f_{\mathrm{y} 1}$ is the design value of tensile strength of tie bar, $f_{t 1}$ is the design value of tensile strength of concrete, $d_{t}$ is the diameter of the tie bar. The number of tie bars through the side surface of the circular truncated cone plug is defined in equation (17), where $s_{1}$ and $s_{2}$ are the distances of the tie bar. The energy dissipation of the tie bars is defined in equation (18), $f_{d}$ is the dynamic factor of the tie bar, $\sigma_{t}$ is the yield strength of the tie bar, (19) can be proposed by substituting equations (15) (17) into equation (18):

$$
\begin{aligned}
l_{e} & =\frac{2}{3} l_{a} \varepsilon_{\mathrm{st}} \\
l_{a} & =\alpha \zeta \frac{f_{y 1}}{f_{t 1}} d_{t} \\
N_{t} & =\frac{\pi\left(\left((d / 2)+H_{c} \tan \theta\right)^{2}-(d / 2)^{2}\right)}{s_{1} s_{2}} \\
W_{t} & =\frac{1}{4} \pi d_{t}^{2} f_{d} \sigma_{t} l_{e} N_{t}
\end{aligned}
$$

$$
W_{t}=\frac{1}{6} \pi^{2} d_{t}^{2} \frac{f_{y 1}}{f_{t 1}} \alpha \zeta \varepsilon_{s t} f_{d} \sigma_{t} \frac{\left((d / 2)+H_{c} \tan \theta\right)^{2}-(d / 2)^{2}}{s_{1} s_{2}} .
$$

Under the condition of the SCS wall with tie bars against the rigid projectile, the perforation velocity $V_{p}$ can be calculated by equation (20); the energy dissipation of each part has been defined in equations (2), (11), (12), and (19) through mechanism analysis:

$$
V_{p}=\sqrt{\frac{2}{M_{1}}\left(W_{s 1}+W_{c o n}+W_{s 2}+W_{t}\right)} .
$$

\section{Comparison Analysis between Formular Results and Test Results}

Details of SCS walls subjected to projectiles were provided in a previous study [19]. The objectives of the actual impact test were to confirm the dynamic impact characteristics of SCS wall models. The projectile diameter was $150 \mathrm{~mm}$ with an overall length of $300 \mathrm{~mm}$. The front end of the projectile had a slight ogive, and the projectile size is shown in Figure 2. The weight of the projectile was approximately $40 \mathrm{~kg}$. The initial impact velocity was accelerated to an impact velocity of approximately $150 \mathrm{~m} / \mathrm{s}$ for all cases. The overall size of the SCS wall model was $2000 \mathrm{~mm} \times 2000 \mathrm{~mm}$, the thickness of the wall was $175 \mathrm{~mm}$ and $250 \mathrm{~mm}$, and the thickness of the steel plate was $6 \mathrm{~mm}$. There was no tie bar in this test wall, and the studs having $13 \mathrm{~mm}$ diameter and $80 \mathrm{~mm}$ length were installed in $150 \mathrm{~mm}$ intervals.

There is no tie bar in the SCS wall in this test, so only the energy dissipation of the front and rear steel plates and concrete is considered. As the projectile nose length is $20 \mathrm{~mm}$, which is much smaller than the projectile diameter of $150 \mathrm{~mm}, \mathrm{~N} 1$ and $\mathrm{N} 2$ can be approximately taken as 1.0 from Chen and $\mathrm{Li}$ [20]. In addition, the values of other relevant parameters in the above-mentioned calculation formulas are shown in Table 1, and a comparison between the calculation results and the test results is shown in Table 2.

The results calculated by the formula showed good agreement with the test results in terms of failure form and residual velocity. Therefore, the proposed calculation formula for perforation prevention of SCS wall based on the energy method is reasonable and feasible. However, there are only two examples in the above-mentioned comparison, the 


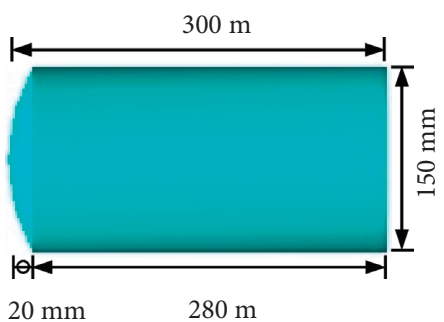

Figure 2: Projectile size.

TABLe 1: Material properties for SCS wall.

\begin{tabular}{lccc}
\hline Parameter & Steel plate & Concrete & Shear stud \\
\hline Density $\left(\mathrm{kg} / \mathrm{m}^{3}\right)$ & $7.8 \times 10^{3}$ & $2.37 \times 10^{3}$ & $7.8 \times 10^{3}$ \\
Yield strength $(\mathrm{MPa})$ & 307 & - & 345 \\
Elastic modulus $(\mathrm{MPa})$ & $2.1 \times 10^{5}$ & 163,238 \\
Thickness $(\mathrm{mm})$ & 6 & - & - \\
$B$ & 1.1 & - & - \\
$n$ & 0.08 & 0.19 & - \\
Tangent modulus $(\mathrm{MPa})$ & 603 & - & 504 \\
Poisson's ratio & 0.3 & - & 0.3 \\
$Q$ & 40 & - & 40 \\
$P$ & 5 & 50.075 \\
Failure strain & 0.28 & 1.9 \\
Compressive strength $(\mathrm{MPa})$ & - & - \\
Design value of tensile strength $(\mathrm{MPa})$ & - & - \\
\hline
\end{tabular}

TABLE 2: Results comparison.

\begin{tabular}{|c|c|c|c|c|c|c|c|}
\hline \multirow{2}{*}{ Case } & \multirow{2}{*}{ Impact velocity $(\mathrm{m} / \mathrm{s})$} & \multicolumn{3}{|c|}{ Failure mode } & \multicolumn{3}{|c|}{ Residual velocity $(\mathrm{m} / \mathrm{s})$} \\
\hline & & Formula & Test & FEM & Formula & Test & FEM \\
\hline SCS-175-6T & 152.4 & Perforation & Perforation & Perforation & 30.6 & 33.9 & 31.1 \\
\hline SCS-250-6T & 147.7 & No perforation & Bulging & Bulging & 0 & 0 & 0 \\
\hline
\end{tabular}

test examples need to be expanded in order to avoid contingency, and a study on SCS wall against projectile by finite element method is performed in the next section to verify the applicability of the formula.

\section{Comparison Analysis between FEM Results and Test Results}

4.1. Development of Finite Element Model. Liu and Zheng [21] used concrete constitutive models, MAT072R3, in FEM simulations of RC structures subjected to a GEJ79 aircraft engine. The analytical results showed good agreement with the test results. Liu et al. $[22,23]$ illustrated that the results correspond well with test $[19,24]$ and DEM results [25] in general for a projectile impacting a SCS structure in case of MAT072R3. So, MAT072R3 is used to model the concrete of the SCS wall in this paper. MAT072R3 is based on Karagozian \& Case (K\&C) Concrete Model-Release III, which is a three-invariant model, uses three shear failure surfaces, includes damage and strain-rate effects, and has origins based on the Pseudo-Tensor Model. MAT072R3 can generate model parameters based on inputting the unconfined compressive strength, density, and Poisson's ratio of the concrete. The strength enhancement factor versus the effective strain rate is given a curve, which was proposed by Malvar and Ross [26]. The input parameters for MAT072R3 in this paper is shown in Table 1. A maximum strain for concrete is set as the element erosion criteria using * MAT_ADD_EROSION in LS-DYNA [27].

MAT003 is suited to model isotropic and kinematic hardening plasticity with the option of including rate effects. MAT003 is employed for material models of projectile and steel plates of SCS wall, in this model the strain rate is accounted for using the Cowper-Symonds model [27, 28]. The hardening parameter is equal to zero in this paper; the dynamic yield strength is defined by equation (21). * CONTACT_AUTOMATIC_SINGLE_SURFACE is used in the contact between projectile, steel plates, and concrete. Concrete is modelled with solid elements, whereas the steel plates and shear studs are modelled with shell elements and beam elements. * CONTACT AUTOMATIC NODES TO SURFACE is used in the contact between projectile and 
shear studs and used in the contact between steel plates and shear studs. The boundary conditions of SCS wall in the impact direction are fixed:

$$
\sigma_{y d}=\sigma_{y}\left(1+\left(\frac{\dot{\varepsilon}}{Q}\right)^{(1 / P)}\right)
$$

where $\sigma_{y d}$ is the dynamic yield strength, $\sigma_{y}$ is the static yield strength, and $Q$ and $P$ are material constants. The parameters of MAT003 input in this paper include density, yield strength, elastic modulus, tangent modulus, Poisson's ratio, $Q, P$, and failure strain. The values of the parameters are shown in Table 1.

4.2. Validation of Finite Element Model. The impact test for SCS-175-6T is the test for the SCS wall which has concrete wall thickness of $175 \mathrm{~mm}$ and steel plate thickness of $6 \mathrm{~mm}$. The test and FEM simulation results of the SCS wall are shown in Figure 3.

The measured impact velocity of the projectile is $152.4 \mathrm{~m} / \mathrm{s}$ and the failure mode is a perforation that is consistent with simulation. The steel plate of the front side is clearly cut and the back plate is torn out as shown in Figure 3. The impact test for SCS-250-6T is the test for the SCS wall which has concrete wall thickness of $250 \mathrm{~mm}$ and steel plate thickness of $6 \mathrm{~mm}$. The test and numerical simulation results of the SCS wall are shown in Figure 4. The measured impact velocity of the projectile is $147.7 \mathrm{~m} / \mathrm{s}$ and the failure mode is bulging that is consistent with simulation. The steel plate of the front side is clearly cut, but the rear plate is not torn out as shown in Figure 4. The projectile is completely inserted into the SCS wall and the SCS wall is bulged significantly at the center.

A comparison of the FEM analysis results and the test results in terms of residual velocity and failure mode is shown in Table 2. The measured residual velocity of the projectile after peroration of SCS-175-6T is $33.9 \mathrm{~m} / \mathrm{s}$, which corresponds closely with $31.1 \mathrm{~m} / \mathrm{s}$ in the simulation. For the two cases, the failure mode and residual velocity simulated by FEM correspond well with those from the test as shown in Figures 3 and 4 and Table 2.

4.3. SCS Wall without Tie Bars Subjected to Blunt Projectile. SCS wall without tie bars in this section is divided into four cases, only the thickness of steel plate and SCS wall is changed, and the projectile material becomes rigid material instead of the elastic-plastic material mentioned above, and other parameters and contact types of the finite element model are consistent with those of Section 4.1. These settings have been tested and verified in Section 4.2.

It requires tedious trial work to get perforation velocity by the finite element calculation and analysis. Because the perforation velocity is that the SCS can be perforated, the residual velocity of the projectile is exactly zero. As shown in Figure 5, when the impact velocity is $134 \mathrm{~m} / \mathrm{s}$, the perforation of the SCS wall does not occur, but when the impact velocity is $135 \mathrm{~m} / \mathrm{s}$, it occurs. It can be seen that the velocity of the projectile at $134 \mathrm{~m} / \mathrm{s}$ becomes zero and has a small rebound velocity after impact, while the final residual velocity of the projectile is about $9 \mathrm{~m} / \mathrm{s}$ in the case of impact velocity at $135 \mathrm{~m} / \mathrm{s}$. In order to get the perforation velocity quickly and conveniently without losing the rationality of the analysis, the method of determining the perforation velocity by FEM in this paper is that the perforation does not occur at a certain impact velocity $V$, the impact velocity will increase by $1 \mathrm{~m} / \mathrm{s}$, and if perforation can occur, the penetration velocity will be $V+1 \mathrm{~m} / \mathrm{s}$. So, the penetration velocity can be accurate to units. As shown in Table 3, a comparison of calculation results of four cases is performed. The calculation results of the formula are close to those obtained by finite element analysis with a deviation of less than $10 \%$. From the comparison results, it can be seen that the calculation formula of antiperforation of SCS wall based on energy method is reasonable and the calculation results are credible.

\subsection{SCS Wall with Tie Bars Subjected to Blunt Projectile.} The perforation velocity of SCS wall with tie bars instead of shear studs subjected to blunt projectile is proposed in this section. The calculation parameters $\alpha$ is $0.16, \zeta$ is 0.6 , the fracture strain $\varepsilon_{s t}$ is 0.3 , and $f_{d}$ is taken equal to 1.2 , respectively. The Design value of the tensile strength of the tie bar is $300 \mathrm{MPa}$, and other parameters are consistent with the shear stud. The distance of tie bars is changed in order to discuss and analyze the effect of tie bars on perforation velocity. A comparison of the perforation velocity of SCS175-4T subjected to blunt projectile is shown in Table 4.

As shown in Table 4, the perforation velocity increases with reducing the distance of tie bars. The results of formula calculation are close to those of finite element analysis with a deviation less than $10 \%$. The energy dissipation of the tie bars corresponding to the distance of $150 \mathrm{~mm}, 75 \mathrm{~mm}$, and $50 \mathrm{~mm}$ are $15232 \mathrm{~J}, 60927 \mathrm{~J}$, and $137087 \mathrm{~J}$, accounting for $4.51 \%, 16.23 \%$, and $30.87 \%$ of the total dissipated energy of SCS wall perforation, respectively. The relationship between shear stud distance and steel plate thickness is defined in equation (22) from Yang [29]; the distance of shear studs is about $92 \mathrm{~mm}$ for SCS-175-4T. The anchorage capacity of tie bars is better than that of studs, and the distance between tie bars is usually larger than that of studs under the same condition. If the distance between tie bars is $75 \mathrm{~mm}$, the energy dissipated by tie bars accounts for $16.23 \%$ of the total energy dissipation, while the energy dissipated by steel plates accounts for $62.04 \%$ of the total energy dissipation. It indicates that the energy dissipated by the steel plate during perforation is much larger than that dissipated by tie bars in normal design:

$$
\frac{D_{d}}{H_{s}}=\sqrt{\frac{\pi^{2} E_{s}}{12 \sigma}}
$$

where $D_{d}$ is the distance of stud, $H_{s}$ is the thickness of steel plate, $E_{s}$ is the elastic modulus of steel plate, $\sigma$ is the yield strength of steel plate.

Some comparisons of perforation velocity for different cases are shown in Tables 5 7. As shown in the tables, 


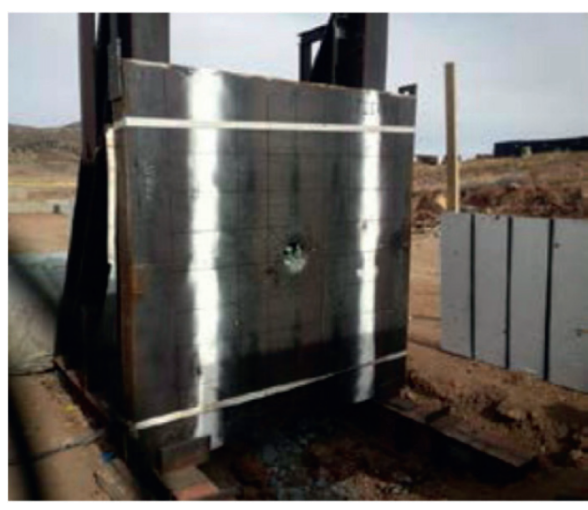

(a)

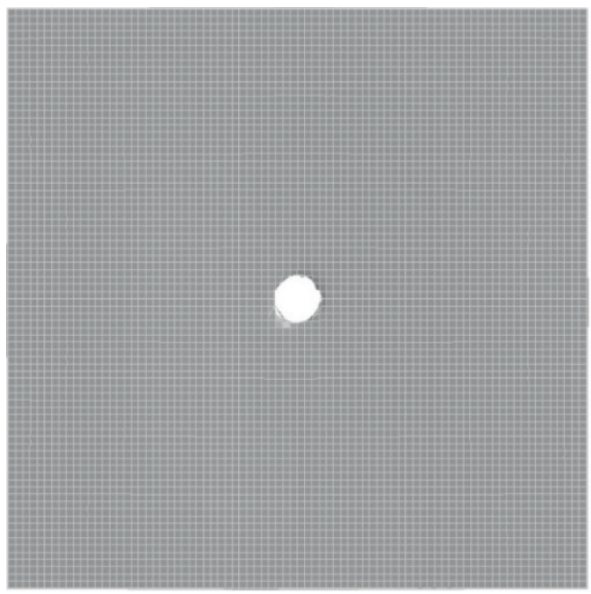

(c)

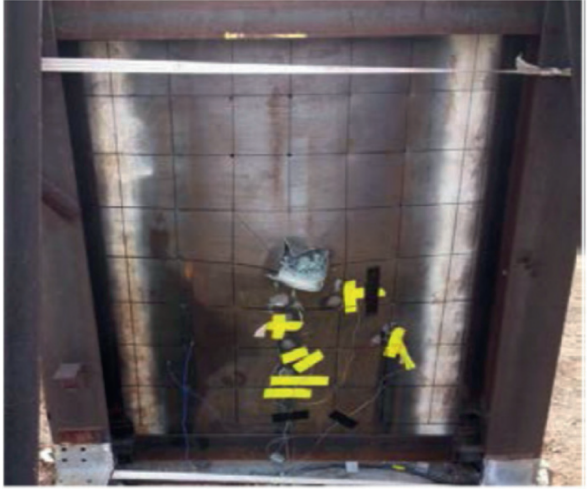

(b)

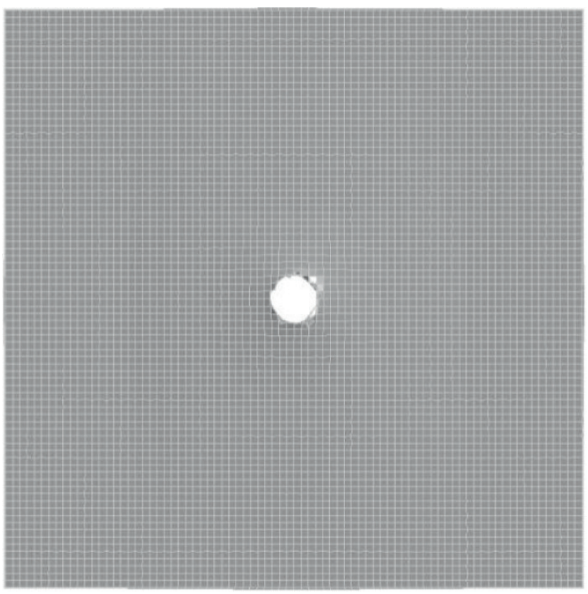

(d)

FIGURE 3: Comparison of SCS wall response (SCS-175-6T). (a) Front steel plate of test. (b) Rear steel plate of test. (c) Front steel plate of FEM simulation. (d) Rear steel plate of FEM simulation.

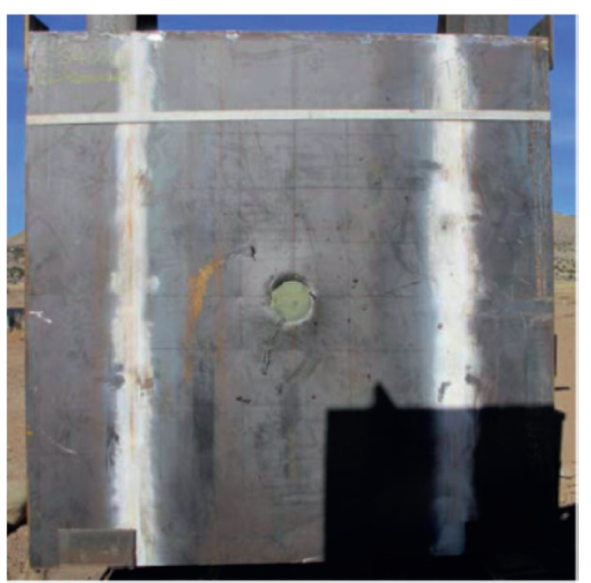

(a)

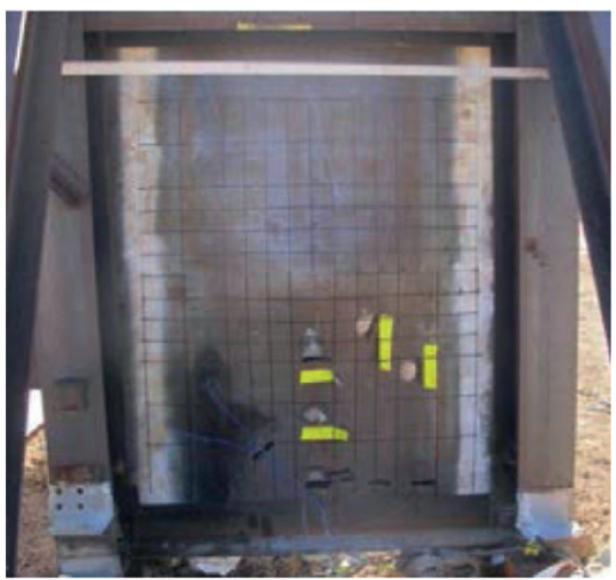

(b)

FIGURE 4: Continued. 


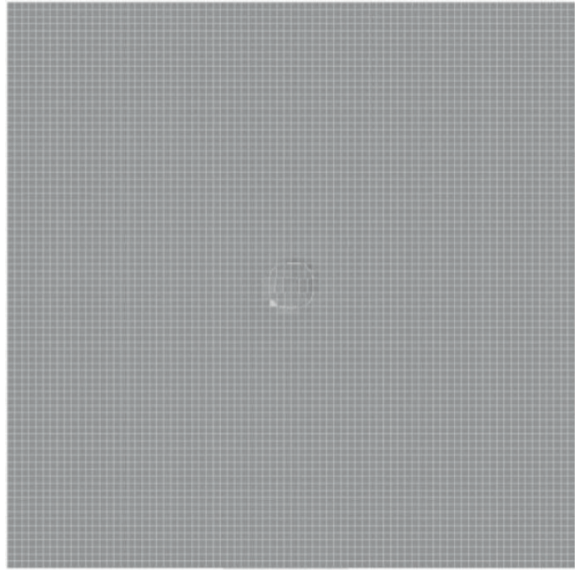

(c)

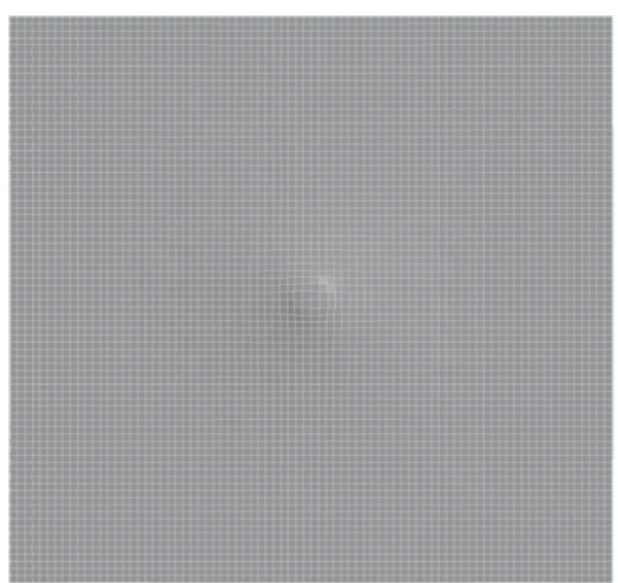

(d)

FIGURE 4: Comparison of SCS wall response (SCS-250-6T). (a) Front steel plate of test. (b) Rear steel plate of test. (c) Front steel plate of FEM simulation. (d) Rear steel plate of FEM simulation.

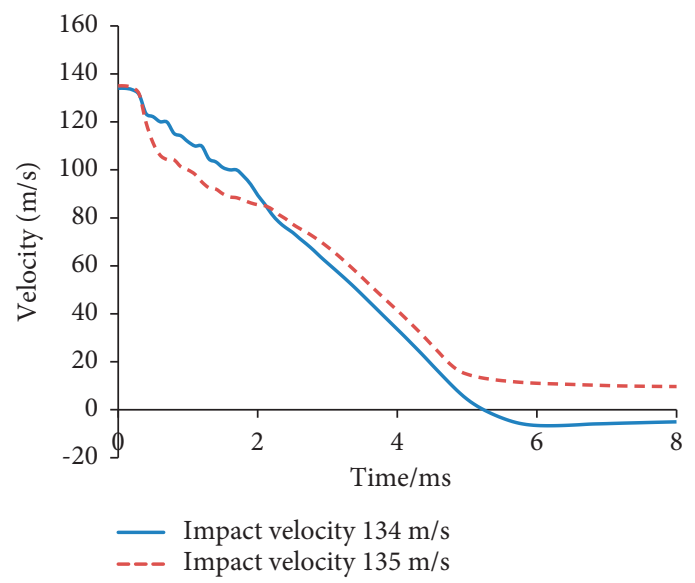

FIGURE 5: Velocity time-history curves of the projectile with different impact velocities for SCS-175-4T.

TABle 3: Perforation velocity comparison of SCS wall without tie bars for blunt projectile.

\begin{tabular}{lccc}
\hline Case & \multicolumn{2}{c}{$\begin{array}{c}\text { Perforation velocity } \\
(\mathrm{m} / \mathrm{s})\end{array}$} & Deviation \\
& Formula & FEM & \\
\hline SCS-175-4T & 127 & 135 & $-5.93 \%$ \\
SCS-175-6T & 146 & 146 & $0 \%$ \\
SCS-250-4T & 148 & 145 & $2.07 \%$ \\
SCS-250-6T & 164 & 160 & $2.5 \%$ \\
\hline
\end{tabular}

TABLE 4: Perforation velocity comparison of SCS-175-4T with a different distance of tie bar for the blunt projectile.

\begin{tabular}{lcccc}
\hline Object & \multirow{2}{*}{$\begin{array}{c}\text { Distance of tie } \\
\text { bar }(\mathrm{mm})\end{array}$} & \multicolumn{2}{c}{ Perforation } \\
velocity $(\mathrm{m} / \mathrm{s})$ & Deviation \\
& & Formula & FEM & \\
\hline \multirow{3}{*}{ SCS-175-4T } & 150 & 130 & 127 & $2.26 \%$ \\
& 75 & 137 & 135 & $1.48 \%$ \\
& 50 & 149 & 151 & $-1.32 \%$ \\
\hline
\end{tabular}

TABLE 5: Perforation velocity comparison of SCS-175-6T with a different distance of tie bar for blunt projectile.

\begin{tabular}{lcccc}
\hline Object & $\begin{array}{c}\text { Distance of tie } \\
\text { bar }(\mathrm{mm})\end{array}$ & \multicolumn{2}{c}{ Perforation } & \\
velocity $(\mathrm{m} / \mathrm{s})$ & Deviation \\
& & Formula & FEM & \\
\hline \multirow{3}{*}{ SCS-175-6T } & 150 & 148 & 147 & $0.68 \%$ \\
& 75 & 155 & 152 & $1.97 \%$ \\
& 50 & 165 & 170 & $-2.94 \%$ \\
\hline
\end{tabular}

perforation velocity increases with the decrease of tie bar distance, and the perforation velocity calculated by the formula is close to the result obtained by finite element analysis with a deviation less than $10 \%$. After calculation, the energy dissipated by the tie bars also accounts for a small proportion of the total energy dissipation.

4.5. SCS Wall with Tie Bars Subjected to Flat Projectile. The working conditions expanded by the test for SCS wall against blunt projectile in the above-mentioned section 
TABLE 6: Perforation velocity comparison of SCS-250-4T with a different distance of tie bar for blunt projectile.

\begin{tabular}{lcccc}
\hline Object & \multirow{2}{*}{$\begin{array}{c}\text { Distance of tie } \\
\text { bar }(\mathrm{mm})\end{array}$} & \multicolumn{2}{c}{ Perforation } & \\
velocity $(\mathrm{m} / \mathrm{s})$ & Deviation \\
& & Formula & FEM & \\
\hline \multirow{3}{*}{ SCS-250-4T } & 150 & 151 & 139 & $8.63 \%$ \\
& 75 & 161 & 160 & $0.63 \%$ \\
& 50 & 176 & 183 & $-3.83 \%$ \\
\hline
\end{tabular}

TABle 7: Perforation velocity comparison of SCS-250-6T with a different distance of tie bar for blunt projectile.

\begin{tabular}{lcccc}
\hline Object & $\begin{array}{c}\text { Distance of tie } \\
\text { bar }(\mathrm{mm})\end{array}$ & \multicolumn{2}{c}{ Perforation } \\
velocity $(\mathrm{m} / \mathrm{s})$ & Deviation \\
& & Formula & FEM & \\
\hline \multirow{3}{*}{ SCS-250-6T } & 150 & 167 & 160 & $4.38 \%$ \\
& 75 & 176 & 173 & $1.73 \%$ \\
& 50 & 190 & 199 & $-4.52 \%$ \\
\hline
\end{tabular}

because of a blunt projectile in the test. The projectile may also be flat-headed in the design of calculation and analysis, so this section mainly focuses on the flat projectile impacting SCS wall, which changes the distance, diameter, and yield strength of tie bar; the thickness and yield strength of steel plate; and the compressive strength of concrete, to perform a comparison of perforation velocity.

4.5.1. The Distance, Diameter, and Yield Strength of Tie Bar. A study on SCS-250-6T subjected to a flat rigid projectile with a mass of $47.57 \mathrm{~kg}$ is performed in this section. The compressive strength of concrete is $50 \mathrm{MPa}$; the distance, diameter, design value of tensile strength, and yield strength of tie bar are $75 \mathrm{~mm}, 13 \mathrm{~mm}, 300 \mathrm{Mpa}$, and $345 \mathrm{MPa}$, respectively. Other calculation parameters are the same as Section 4.4. Perforation velocity comparison of SCS-250-6T with different conditions of the tie bar is shown in Table 8 .

As shown in Table 8, the formular results are close to the FEM results with a small deviation. The results of formular calculation corresponding to $150 \mathrm{~mm}, 75 \mathrm{~mm}$, and $50 \mathrm{~mm}$ of the tie bar distance are $152 \mathrm{~m} / \mathrm{s}, 160 \mathrm{~m} / \mathrm{s}$, and $173 \mathrm{~m} / \mathrm{s}$, and the results of finite element analysis are $147 \mathrm{~m} / \mathrm{s}, 167 \mathrm{~m} / \mathrm{s}$, and $178 \mathrm{~m} / \mathrm{s}$, respectively. Compared with $150 \mathrm{~mm}, 75 \mathrm{~mm}$, and $50 \mathrm{~mm}$ of the tie bar distance is reduced by $50 \%$ and about $67 \%$, respectively, and the corresponding perforation velocity calculated by FEM is increased by about $13.61 \%$ and $21.09 \%$, respectively. The diameters of $13 \mathrm{~mm}, 16 \mathrm{~mm}$, and $20 \mathrm{~mm}$ of tie bar are increased from $10 \mathrm{~mm}$ by $30 \%, 60 \%$, and $100 \%$, respectively, and the corresponding perforation velocity calculated by FEM is increased by $9.15 \%, 13.73 \%$, and $15.03 \%$, respectively. The yield strength of $345 \mathrm{MPa}$ and $400 \mathrm{MPa}$ of the tie bar is increased from $307 \mathrm{MPa}$ by $12.38 \%$ and $30.29 \%$, and the corresponding perforation velocity calculated by FEM is increased by $2.45 \%$ and $4.91 \%$, respectively.

4.5.2. The Thickness and Yield Strength of Steel Plate. The masses of the flat rigid projectile are $47.57 \mathrm{~kg}$ and $88.35 \mathrm{~kg}$. The compressive strength of concrete is $50 \mathrm{MPa}$; the distance, diameter, design value of tensile strength, and yield strength of tie bar are $75 \mathrm{~mm}, 13 \mathrm{~mm}, 300 \mathrm{Mpa}$, and $345 \mathrm{MPa}$, respectively. Perforation velocity comparison for different conditions of steel plate is shown in Table 9.

As shown in Table 9, the formular results are close to the FEM results with a deviation less than $10 \%$ except that the deviation of SCS-250-20T is $10.55 \%$. Compared with $4 \mathrm{~mm}$, $6 \mathrm{~mm}$, and $8 \mathrm{~mm}$ of the steel plate thickness is increased by $50 \%$ and $100 \%$, respectively, and the corresponding perforation velocity calculated by FEM is increased by about $21.01 \%$ and $33.33 \%$, respectively. The thickness of $15 \mathrm{~mm}$ and $20 \mathrm{~mm}$ of steel plate is increased from $10 \mathrm{~mm}$ by $50 \%$ and $100 \%$, respectively, and the corresponding perforation velocity calculated by FEM is increased by $12.00 \%$ and $32.67 \%$, respectively. The yield strength of $307 \mathrm{MPa}$, $345 \mathrm{MPa}$, and $400 \mathrm{MPa}$ of steel plate is increased from $250 \mathrm{MPa}$ by $22.8 \%, 38 \%$, and $60 \%$, and the corresponding perforation velocity calculated by FEM is increased by $6.37 \%, 7.64 \%$, and $12.74 \%$, respectively.

4.5.3. The Compressive Strength of Concrete. The masses of the flat rigid projectile is $47.57 \mathrm{~kg}$. The distance, diameter, design value of tensile strength, and yield strength of tie bar is $75 \mathrm{~mm}, 13 \mathrm{~mm}, 300 \mathrm{MPa}$, and $345 \mathrm{MPa}$, respectively. The thickness and yield strength of the steel plate are $6 \mathrm{~mm}$ and $307 \mathrm{MPa}$. The compressive strength of concrete is from $30 \mathrm{MPa}$ to $60 \mathrm{MPa}$ in $5 \mathrm{MPa}$ increments.

As shown in Table 10, the formular results are close to the FEM results with a deviation less than $10 \%$ for different compressive strengths of concrete. The compressive strength of $35 \mathrm{MPa}, 40 \mathrm{MPa}, 45 \mathrm{MPa}, 50 \mathrm{MPa}, 55 \mathrm{MPa}, 60 \mathrm{MPa}$ of concrete is increased from $30 \mathrm{MPa}$ by $16.67 \%, 33.33 \%, 50 \%$, $66.67 \%, 83.33 \%$, and $100 \%$, respectively, and the corresponding perforation velocity calculated by the formula is increased by $3.27 \%, 3.92 \%, 4.58 \%, 9.15 \%, 9.80 \%$, and $11.11 \%$, respectively.

4.5.4. Analysis of Effect of Different Factors on Perforation Velocity. In order to simply analyze the effect of different factors on perforation velocity, a net increased ratio index can be defined to evaluate this influence, and a calculation formula of net increased ratio is shown in equation (23), where $r_{v}$ is the change rate of perforation velocity and $r_{f}$ is the change rate of influence factor:

$$
N_{r}=\left|\frac{r_{v}}{r_{f}}\right| \text {. }
$$

Generally, the bigger the net increased ratio is, the greater influence of this factor on perforation velocity is. According to equation (23), the calculation results of the net increased ratio of various factors are shown in Table 11. As shown, the influence of factors on perforation velocity can be roughly divided into three categories: the influence of the thickness of steel plate and distance of tie bar is the largest effect, followed by that of yield strength of steel plate, yield strength of tie bar and diameter of tie bar, and that of compressive strength of concrete is the smallest effect. 
TABLE 8: Perforation velocity comparison of SCS-250-6T with different conditions of tie bar for flat projectile.

\begin{tabular}{|c|c|c|c|c|c|c|c|}
\hline \multirow[t]{2}{*}{ Object } & \multirow{2}{*}{$\begin{array}{l}\text { Distance of tie } \\
\text { bar }(\mathrm{mm})\end{array}$} & \multirow{2}{*}{$\begin{array}{l}\text { Diameter of tie } \\
\text { bar }(\mathrm{mm})\end{array}$} & \multirow{2}{*}{$\begin{array}{l}\text { Yield strength of tie } \\
\text { bar }(\mathrm{MPa})\end{array}$} & \multirow{2}{*}{$\begin{array}{l}\text { Design value of tensile } \\
\text { strength of tie bar }(\mathrm{MPa})\end{array}$} & \multicolumn{2}{|c|}{$\begin{array}{c}\text { Perforation } \\
\text { velocity }(\mathrm{m} / \mathrm{s})\end{array}$} & \multirow[t]{2}{*}{ Deviation } \\
\hline & & & & & Formula & FEM & \\
\hline \multirow{8}{*}{ SCS-250-6T } & 150 & 13 & 345 & 300 & 152 & 147 & $3.40 \%$ \\
\hline & 75 & 13 & 345 & 300 & 160 & 167 & $-4.19 \%$ \\
\hline & 50 & 13 & 345 & 300 & 173 & 178 & $-2.81 \%$ \\
\hline & 75 & 10 & 345 & 300 & 154 & 153 & $0.65 \%$ \\
\hline & 75 & 16 & 345 & 300 & 169 & 174 & $-2.87 \%$ \\
\hline & 75 & 20 & 345 & 300 & 180 & 176 & $2.27 \%$ \\
\hline & 75 & 13 & 307 & 270 & 157 & 163 & $-3.68 \%$ \\
\hline & 75 & 13 & 400 & 360 & 164 & 171 & $-4.09 \%$ \\
\hline
\end{tabular}

TABLE 9: Perforation velocity comparison of SCS wall with different conditions of steel plate for flat projectile.

\begin{tabular}{|c|c|c|c|c|c|c|}
\hline \multirow{2}{*}{ Object } & \multirow{2}{*}{$\begin{array}{c}\text { Mass of } \\
\text { projectile }(\mathrm{kg})\end{array}$} & \multirow{2}{*}{$\begin{array}{c}\text { Thickness of steel } \\
\text { plate }(\mathrm{mm})\end{array}$} & \multirow{2}{*}{$\begin{array}{l}\text { Yield strength of } \\
\text { steel plate }(\mathrm{MPa})\end{array}$} & \multicolumn{2}{|c|}{$\begin{array}{l}\text { Perforation velocity } \\
\qquad(\mathrm{m} / \mathrm{s})\end{array}$} & \multirow[t]{2}{*}{ Deviation } \\
\hline & & & & Formula & FEM & \\
\hline \multirow[t]{2}{*}{ SCS-250-4T } & 47.57 & 4 & 307 & 144 & 138 & $4.35 \%$ \\
\hline & 47.57 & 6 & 250 & 153 & 157 & $-2.55 \%$ \\
\hline \multirow{3}{*}{ SCS-250-6T } & 47.57 & 6 & 307 & 160 & 167 & $-4.19 \%$ \\
\hline & 47.57 & 6 & 345 & 164 & 169 & $-2.96 \%$ \\
\hline & 47.57 & 6 & 400 & 170 & 177 & $-3.95 \%$ \\
\hline SCS-250-8T & 47.57 & 8 & 307 & 174 & 184 & $-5.43 \%$ \\
\hline SCS-250-10T & 88.35 & 10 & 307 & 137 & 150 & $-8.67 \%$ \\
\hline SCS-250-15T & 88.35 & 15 & 307 & 159 & 168 & $-5.36 \%$ \\
\hline SCS-250-20T & 88.35 & 20 & 307 & 178 & 199 & $-10.55 \%$ \\
\hline
\end{tabular}

TABLE 10: Perforation velocity comparison of SCS wall with different conditions of concrete for the flat projectile.

\begin{tabular}{lcccc}
\hline Object & $\begin{array}{c}\text { Compressive strength of } \\
\text { concrete }(\mathrm{MPa})\end{array}$ & \multicolumn{2}{c}{ Perforation velocity (m/s) } & FEM \\
\hline & 30 & 145 & 153 & $-5.23 \%$ \\
& 35 & 148 & 158 & $-6.33 \%$ \\
SCS-250-6T & 40 & 151 & 159 & $-5.03 \%$ \\
& 45 & 155 & 160 & $-3.13 \%$ \\
& 50 & 160 & 167 & $-4.19 \%$ \\
& 55 & 165 & 168 & $1.79 \%$ \\
\hline
\end{tabular}

TABLE 11: Effect comparison of different factors on perforation velocity.

\begin{tabular}{|c|c|c|c|c|c|c|c|}
\hline \multirow{2}{*}{ Factor } & \multicolumn{3}{|c|}{ Factor variation } & \multicolumn{3}{|c|}{ Perforation velocity variation } & \multirow{2}{*}{$N_{r}$} \\
\hline & Value 1 & Value 2 & $r_{f}$ & Value 1 & Value 2 & $r_{v}$ & \\
\hline Distance of tie bar (mm) & 150 & 50 & $-66.67 \%$ & 147 & 178 & $21.09 \%$ & $31.63 \%$ \\
\hline Diameter of tie bar $(\mathrm{mm})$ & 10 & 20 & $100 \%$ & 153 & 176 & $15.03 \%$ & $15.03 \%$ \\
\hline Yield strength of tie bar (MPa) & 307 & 400 & $30.29 \%$ & 163 & 171 & $4.91 \%$ & $16.20 \%$ \\
\hline Thickness of steel plate $(\mathrm{mm})$ & 4 & 8 & $100 \%$ & 138 & 184 & $33.33 \%$ & $33.33 \%$ \\
\hline Yield strength of steel plate (MPa) & 250 & 400 & $60 \%$ & 157 & 177 & $12.74 \%$ & $21.23 \%$ \\
\hline Compressive strength of concrete (MPa) & 30 & 60 & $100 \%$ & 153 & 170 & $11.11 \%$ & $11.11 \%$ \\
\hline
\end{tabular}

\section{Conclusions and Suggestions}

(1) In order to study local damage of SCS walls which is used in the third generation of nuclear power plants caused by aircraft engine or missile impact, a calculation method of SCS wall to resist perforation from rigid projectile based on energy method is proposed in this paper, which accounts for the 
perforation of the concrete and steel plates separately and accounts for the interaction between them; the energy is divided into four parts, namely, the energy dissipated by front steel plate, concrete, rear steel plate, and tie bars. A practical antiperforation calculation formula of SCS wall with tie bars is given.

(2) The rationality and feasibility of the given calculation formula are verified by comparing its calculation results with existing test data and dozens of finite element analysis results. The formular results are close to the FEM results with a deviation less than $10 \%$ except for a working condition with a deviation of $10.55 \%$, which shows that the calculation formula given in this paper is reasonable and credible to effectively evaluate perforation failure of SCS wall and carry out a relevant design.

(3) In the comparative analysis of dissipated energy, the energy dissipated by the steel plate is much larger than that of the tie bars. The effect of various factors on perforation velocity is analyzed according to finite element calculation results, which can be roughly divided into three categories: the influence of the thickness of steel plate and distance of tie bar is the largest effect, followed by that of yield strength of steel plate, yield strength of tie bar, and diameter of the tie bar, and that of compressive strength of concrete is the smallest effect.

(4) Additional research is recommended to further evaluate the influence of concrete thickness on perforation velocity and the adaptability of the antiperforation calculation formula to different projectile noses and higher impact velocities.

\section{Data Availability}

The data used to support the findings of this study are available from the corresponding author upon request.

\section{Conflicts of Interest}

The authors declare that they have no conflicts of interest.

\section{Acknowledgments}

This study was supported by the National Science and Technology Major Project of China (Grant no. 2018ZX06902016).

\section{References}

[1] R. P. Kennedy, "A review of procedures for the analysis and design of concrete structures to resist missile impact effects," Nuclear Engineering and Design, vol. 37, no. 2, pp. 183-203, 1976.

[2] M. Y. H. Bangash, Concrete and concrete Structures: Numerical Modelling and Applications, Elsevier Applied Science, London, UK, 1989.

[3] R. Ranjan, S. Banerjee, R. K. Singh, and P. Banerji, "Local impact effects on concrete target due to missile: an empirical and numerical approach," Annals of Nuclear Energy, vol. 68, pp. 262-275, 2014.

[4] M. S. Williams, "Modelling of local impact effects on plain and reinforced concrete," ACI Structure Journal, vol. 91, no. 2, pp. 178-187, 1994.

[5] H. M. Wen, "Empirical equations for the impact response of concrete targets," Explosion and Shock Waves, vol. 23, no. 3, pp. 267-274, 2003.

[6] Q. M. Li, S. R. Reid, H. M. Wen, and A. R. Telford, "Local impact effects of hard missiles on concrete targets," International Journal of Impact Engineering, vol. 32, no. 1-4, pp. 224-284, 2005.

[7] C. M. Song, M. Y. Wang, and D. R. Wang, "Calculating method for local damage of RC containment under impact," Journal of Wuhan University of Technology, vol. 35, no. 7, pp. 113-117, 2013.

[8] S. F. Feng, R. Du, and D. R. Wang, "Calculation research on punching shearresistance of reinforced concrete containment under accident impact," Industrial Construction, vol. 41, pp. 137-139, 2011.

[9] Q. M. Li and D. J. Tong, "Perforation thickness and ballistic limit of concrete target subjected to rigid projectile impact," Journal of Engineering Mechanics, vol. 129, no. 9, pp. 10831091, 2003.

[10] Q. M. Li, S. R. Reid, and A. M. Ahmad-Zaidi, "Critical impact energies for scabbing and perforation of concrete target," Nuclear Engineering and Design, vol. 236, no. 11, pp. 11401148, 2006.

[11] X. W. Chen, X. L. Li, F. L. Huang, H. J. Wu, and Y. Z. Chen, "Normal perforation of reinforced concrete target by rigid projectile," International Journal of Impact Engineering, vol. 35, no. 10, pp. 1119-1129, 2008.

[12] H. Grisaro and A. N. Dancygier, "Assessment of the perforation limit of a composite RC barrier with a rear steel liner to impact of a non-deforming projectile," International Journal of Impact Engineering, vol. 64, pp. 122-136, 2014.

[13] N. A. Siddiqui, B. M. A. Khateeb, T. H. Almusallam, Y. A. AlSalloum, R. A. Iqbal, and H. Abbas, "Reliability of RC shielded steel plates against the impact of sharp nose projectiles," International Journal of Impact Engineering, vol. 69, pp. 122-135, 2014.

[14] J. C. Bruhl, A. H. Varma, and W. H. Johnson, "Design of composite SC walls to prevent perforation from missile impact," International Journal of Impact Engineering, vol. 75, pp. 75-87, 2015.

[15] X. W. Chen, X. L. Huang, and G. J. Liang, "Comparative analysis of perforation models of metallic plates by rigid sharp-nosed projectiles," International Journal of Impact Engineering, vol. 38, no. 7, pp. 613-621, 2011.

[16] M. J. Forrestal and T. L. Warren, "Perforation equations for conical and ogival nose rigid projectiles into aluminum target plates," International Journal of Impact Engineering, vol. 36, no. 2, pp. 220-225, 2009.

[17] A. K. Kar, "Residual velocity for projectiles," Nuclear Engineering and Design, vol. 53, no. 1, pp. 87-95, 1979.

[18] Ministry of Housing and Urban-Rural Development of the People's Republic of China, Code For Design of Concrete Structures, China Architecture \& Building Press, Beijing, China, 2015.

[19] K.-s. Kim, I.-h. Moon, H.-j. Choi, and D.-w. Nam, “A preliminary study on the local impact behavior of steel-plate concrete walls," Annals of Nuclear Energy, vol. 102, pp. 210219, 2017. 
[20] X. W. Chen and Q. M. Li, "Deep penetration of a non-deformable projectile with different geometrical characteristics," International Journal of Impact Engineering, vol. 27, no. 6, pp. 619-637, 2002.

[21] J. B. Liu and W. K. Zheng, "Impact load analysis on a nuclear power plant impacted by a large commercial aircraft," Journal of Vibration and Shock, vol. 33, no. 6, pp. 97-112, 2014.

[22] J. B. Liu and P. F. Han, "Numerical analyses of a shield building subjected to a large commercial aircraft impact," Shock and Vibration, vol. 2018, Article ID 7854969, 17 pages, 2018.

[23] P. F. Han, J. B. Liu, and B. G. Fei, "Comparative analyses of a shield building subjected to a large commercial aircraft impact between decoupling method and coupling method," Nuclear Engineering And Technology, vol. 87, 2021.

[24] J. Mizuno, N. Koshika, Y. Sawamoto, N. Niwa, T. Yamashita, and A. Suzuki, "Investigation on impact resistance of steel plate reinforced concrete barriers against aircraft impact part1: test program and results," in Proceedings of the 18th International Conference on Structural Mechanics in Reactor Technology, pp. 2566-2579, Beijing, China, August 2005.

[25] J. Mizuno, N. Koshika, H. Morikawa, K. Wakimoto, K. Kobayashi, and R. Fukuda, "Investigation on impact resistance of steel plate reinforced concrete barriers against aircraft impact part 2: simulation analyses of scale model impact tests," in Proceedings of the 18th International Conference on Structural Mechanics in Reactor Technology, pp. 2580-2590, Beijing, China, August 2005.

[26] L. J. Malvar and C. A. Ross, "Review of strain rate effects for concrete in tension," ACI Materials Journal, vol. 95, no. 6, pp. 735-739, 1998.

[27] Livermore Software Technology Corporation, LS-DYNA Keyword User's Manual, Version 971, Livermore Software Technology Corporation, Livermore, CA, USA, 2012.

[28] N. Jones, Structural Impact, Cambridge University Press, Cambridge, UK, 1989.

[29] Y. Yang, Seismic behavior of double-skin-composite containment structures in nuclear engineering, Ph.D. Dissertation, Tsinghua University, Beijing, China, 2015. 